University of Nebraska - Lincoln

DigitalCommons@University of Nebraska - Lincoln

2011

Impact of Signal Timing Information on Safety and Efficiency of Signalized Intersections

Anuj Sharma

University of Nebraska at Lincoln, anujs@iastate.edu

Follow this and additional works at: https://digitalcommons.unl.edu/civilengfacpub

Part of the Civil Engineering Commons

Sharma, Anuj, "Impact of Signal Timing Information on Safety and Efficiency of Signalized Intersections" (2011). Civil Engineering Faculty Publications. 39.

https://digitalcommons.unl.edu/civilengfacpub/39

This Article is brought to you for free and open access by the Civil Engineering at DigitalCommons@University of Nebraska - Lincoln. It has been accepted for inclusion in Civil Engineering Faculty Publications by an authorized administrator of DigitalCommons@University of Nebraska - Lincoln. 


\title{
IMPACT OF SIGNAL TIMING INFORMATION ON SAFETY AND EFFICIENCY OF SIGNALIZED INTERSECTIONS
}

\author{
Anuj Sharma ${ }^{1}$; Lelitha Vanajakshi $^{2}$; Girish, V ${ }^{3}$; Harshitha, M. S. ${ }^{4}$
}

\begin{abstract}
Signalized intersections are provided in traffic networks to improve the safety
\end{abstract} and efficiency of vehicular and pedestrian movement. There are various measures under education, enforcement and engineering headings that are being attempted to improve safety and efficiency of operations at a signalized intersection. Provision of signal countdown timer, a timer showing the remaining red and green time in a phase, is one such measure and is commonly adopted in India. However, studies on effects of countdown timer under Indian traffic conditions are very scarce. Traffic heterogeneity and lack of lane discipline makes transferability of models developed in other countries (with more organized traffic) infeasible. The present study is an attempt to analyze the changes in queue discharge characteristics and red light violations (RLV) under Indian traffic conditions due to the presence of timer. A before and after analysis was carried out using the data collected from a selected intersection in Chennai, India. The analysis is carried out for different vehicle types in the presence and absence of timers separately for the start and end of red/green. Results showed that the information provided at the start of green (end of red) enhances efficiency, the startup lost time is reduced and there is an increase in red light violations. Two wheelers present at the start of the queue are found to be the category that is mostly affected by this information. However, the information provided at end of green (start of red) was found to reduce the red light violations. In the presence of information, it was found that the

\footnotetext{
${ }^{1}$ Assistant Professor, University of Nebraska Lincoln, Department of Civil Engineering, Nebraska Hall W348 Lincoln, NE 68588-0531;Phone: (402) 472-6391;E-mail: asharma@unl.edu

${ }^{2}$ Corresponding Author, Assistant Professor, Department of Civil Engineering, Indian Institute of Technology Madras, Chennai 600 036, INDIA; Phone: 91442257 4291;E-mail: lelitha@iitm.ac.in

${ }^{3}$ Former Masters student, Department of Civil Engineering, Indian Institute of Technology Madras, Chennai 600 036

${ }^{4}$ Undergraduate student, Department of Civil Engineering, National Institute of Technology Calicut, INDIA
} 
propensity of RLV (proportion of cycles having RLV) reduced from $59 \%$ to $31 \%$ at the end of green (start of red) and there was an increase from $12 \%$ to $75 \%$ at the start of green (end of red) with statistically significant drop in the headways (indicating an increased efficiency). Also, in presence of information, the intensity of RLV (Mean RLVs per RLV cycle) for both start of red and end of red reduced from 3.32 to 2.30 vehicles and 8.52 to 5.60 vehicles respectively. The impacts varied based on the vehicle types with major impacts on the two wheelers. The queue discharge models show a significant change in trend implying a need to update the signal timings when the timer's are installed. These results also bring into light the trade-off between safety and efficiency and the choices drivers make in the presence of phase change information. These trade-offs should be carefully considered as the technology advances and drivers are provided more and more information. For example, with the advent of intellidrive technology (vehicle to infrastructure communications), the extent of information provided to the drivers should be tailored to achieve system optimality and results from studies such as the present one can help in decision making.

Keywords: Safety and efficiency of signalized intersections; Countdown signal timers; Discharge headway; Red light violation.

\section{INTRODUCTION}

The efficiency of an urban roadway system depends heavily on the efficiency of the signalized intersections, since they are one of the main bottleneck causes in urban roadways. Signalized intersections are introduced to increase efficiency and reduce accidents in the road network. Several measures are adopted to increase the safety and efficiency of these signalized intersections. These measures can be grouped under three headings, namely, engineering, education and enforcement. Countdown timers are one such measure which can fall under the engineering heading and is becoming more popular in many countries including India. 
A countdown timer indicates the time remaining for the phase change, which makes drivers more prepared to respond to the signal change. The phase information is expected to affect driver behavior. Such timers are becoming more popular in many countries and have been installed in many intersections in India. However, scientific studies in this area under Indian conditions are very limited, and those that are available in literature compared different intersections with and without timers (Sharma et al. 2009). Studies from other countries in this area reports mixed results, as detailed in the literature review. Further, since driver behavior varies widely between countries, there is a need for separate studies from different geographical locations. The present study concentrates on the effect of these timers on the queue discharge characteristics and propensity and intensity of red light violations (RLV) at a signalized intersection under Indian traffic conditions.

Indian traffic being heterogeneous and less lane disciplined, special care was taken to include these features in the analysis. To take heterogeneity into account, classified analysis was carried out for each type of vehicle. The classification considered includes two-wheelers, three wheelers and cars. In the case of headway, the classification was made based on the following vehicle, making the assumption that the following vehicle mainly decides the gap to be left between the vehicles. The lack of lane discipline is another feature of Indian traffic which causes much difficulty with data collection and analysis. In the present study this issue is tackled by not analyzing the data lane by lane, but by considering the road width as a whole and noting down the headway, whenever two of the vehicles are following one another. Sampled data were collected making sure that observations under each category were obtained in each interval.

The section below briefly describes the available literature in this area and is followed by a section detailing the data collection process. The analysis of data is presented next followed by results and discussions. 


\section{LITERATURE REVIEW}

Since the present study concentrates on the effect of timers on queue discharge headway and RLV, the literature in these two areas are briefly discussed in this section.

\section{Queue Discharge Headway}

Discharge headway is the time difference between consecutive vehicles at a reference point when they move during the green phase. The first vehicle's headway is measured as the time elapsed from the start of green to the time it crosses the reference line. The second headway is the time between the first and second vehicle, etc. Common practice is to measure the headways as the rear wheels of the reference vehicle cross the curb line. If the measurement does not include the vehicle length, which is the time difference between the rear of the previous vehicle to the front of the next vehicle, it is referred to as gap.

Earlier studies reported the first few headways to be higher since they include the reaction time of the drivers, which will get shorter with every subsequent driver in the line with the reaction times overlapping. Finally, headways/gaps tend to level out to the minimum headway/gap value. This generally occurs when vehicles have fully accelerated by the time they reach the reference line. It is reported that this "leveling off" begins with the fourth or fifth headway/gap (Roger et al. 1998). Figure 1 represents this ideal change in headway. This is the accepted norm at present with the first vehicle having the maximum headway, which will decrease for consecutive vehicles and reach a constant headway after the $4^{\text {th }}$ or $5^{\text {th }}$ vehicle. The accepted value of constant headway after it levels out is 1.9 seconds in the Highway Capacity Manual (2000).

Many studies report the above observation of headway being high at the start of green and leveling off after the $4^{\text {th }}$ or $5^{\text {th }}$ vehicle (Greenshields, 1947; Carstens, 1971; Kunzman, 1978; Moussavi, and Tarawneh, 1990). Though all these studies showed the standard trend of headway becoming constant after few initial vehicles, over the years the 
studies showed a gradual reduction in this start up lost time (which is the main reason for larger headway at the start of green), with more aggressive driving habits and better acceleration performance of vehicles. Lu (1984) analyzed the protected and unprotected leftturn vehicles at signalized intersections and showed that smaller vehicles require smaller discharge headways. Also, it was reported that left-turn vehicles had lower discharge headway values than the other vehicles. Lee and Chen (1986) examined the sensitivity of different factors affecting the discharge headway of straight-through movement of passenger cars. It was found that the approach speed limits and queue length significantly influenced the discharge headway. Parker (1996) investigated the effect of heavy vehicles on discharge headway of the following vehicles. It was found that vehicle size of leading and following vehicles had important bearings on the discharge headway. Tong and Hung (2002) proposed a neural network (NN) approach to simulate the queued vehicle discharge headway. Khosla and Williams (2006) studied the effect of length of green phase at an intersection on vehicle headways and showed no significant difference in vehicle headways when the green time is increased.

However, as can be seen from the literature review, majority of the above studies were based on data from homogeneous, lane disciplined traffic conditions. These observations may not be true for the heterogeneous, less lane disciplined traffic such as that in India. Under Indian conditions, since vehicles do not wait in queue, such an observation with respect to queue position will not be possible. One can observe with respect to time from start of green and check for a similar trend. Also, many of the intersections in India and other Asian countries are being equipped with countdown timers that display the time left before the signal indication change. Though these timers are more informative in nature, they will affect many traffic characteristics including discharge headway. For example, with the extra information of the time remaining for the green indication to start, drivers will be much more alert which will reduce the initial lost time. However, studies on the impact of 
countdown timers on queue discharge patterns are limited under heterogeneous conditions (Ibrahim et al. 2008; Sharma et al. 2009; Limanond, et al. 2009; Chiou and Chang 2010) and most of them were focusing on one geographic area, had only limited data, or analysed data from different intersections. This highlights a need for additional studies to investigate the signal countdown impact in detail, and perhaps the need to perform similar studies in different geographical areas with a larger sample size and data being collected from the same intersection, with and without a timer. The present study takes into account these limitations and analyses the discharge headway variation at signalized intersection under Indian traffic conditions with data collected from the same location which will help in reaching the absolute values of minimum headway and how it is comparable under with and without timer scenario.

\section{Red Light Violations}

As per the FHWA information guide (FHWA-HRT-04-091) on signalized intersections, one primary cause of collisions at signalized intersections is a motorist entering an intersection when the red signal is displayed, and as a consequence colliding with another motorist, pedestrian, or bicyclist who is legally within the intersection. Another FHWA report (Report number FHWA-RD-00-112) shows that red light runners cause 16 to $20 \%$ of all collisions at signalized intersections. Countermeasures proposed to address red light running include removal of unwarranted traffic signals, changing the signal timing, improving the visibility of the traffic signal, or enforcement (FHWA-HRT-04-091). Several studied the effect of one or more of the above measures on RLV and are briefly listed below, grouped under three headings.

\section{Enforcement Cameras}


Video camera enforcement of red light violations has been adopted as a measure for enhancing safety at intersections. Retting et al. (2003) reviewed and evaluated the international literature regarding the effectiveness of cameras to reduce both red light violations and crashes and reported that, overall, injury crashes including rear-end collisions, were reduced by $25-30 \%$ as a result of camera enforcement. Effect of enforcement cameras was also studied by Martinez and Porter (2006) based on data from Virginia, USA and reported a decrease in overall red light running at camera sites. They also reported that the characteristics of a typical red light runner remained the same at camera and non-camera locations. Lum and Wong (2002, 2003) used a logit model (2002) and generalized linear modeling (2003) and reported that the propensity to stop at camera approaches about 17 times more than at non-camera approaches based on their study in Singapore. Thomas and Hess (2009) studied the effect of red-light cameras for the prevention of road traffic crashes and concluded that the cameras are effective in reducing total casualty crashes.

\section{Engineering}

Optimally designed signal timing plans have been reported to impact the propensity of red light violations. Retting and Greene (1997) showed in their study that the dilemma zone acts as a major influencing parameter on red light violation. Retting et al. (2008) showed that the provision of adequate yellow signal timing reduces red light running to some extent, and effective enforcement by red light cameras to support it can be effective in reducing red light violations. Horst (1988) also analyzed the effect of the length of the yellow interval on driver decision making. Datta et al. (2000a, 2000b) compared the red light violation characteristics at intersections in Michigan, USA, with all-red intervals and those without all-red intervals. The studies indicated a significantly lower red light violation rate at the traffic signals with all-red intervals as compared to the intersections where there were no all-red intervals or 
insufficient all-red intervals. Studies on the effect of yellow intervals (Mahalel and Zaidel, 1985a), flashing green (Mahalel and Zaidel, 1985b), and flashing amber (Newton et al. 1997) on RLV were also reported.

Porter and England (2000) analyzed yellow runners and red runners separately and carried out a prediction of red light running by considering driver characteristics. Craig et al. (1997) reported on the effect of a new signal phasing system, which will help drivers to make safe stopping or crossing decisions, and reported a reduction in red light violations due to the system. Grembek et al. (2009) also reported a study on the development of enhanced signal timing models for possible reduction of red light running (RLR). They used discrete choice models to determine the significant influencing factors of RLR including traffic and control characteristics and using that to find the enhanced signal timing plans that can potentially reduce RLR.

\section{Information}

From a theoretical perspective, the timing display is also a communication device and there are many studies which analyzed how timers or other communication devices are expected to affect driver behavior. Lum and Halim (2006) investigated the driver response at a signalized intersection approach installed with a green signal countdown device in Singapore. The impacts of pedestrian countdown signals on driver behavior was studied by Nambisan and Karkee (2010) and Huey and Ragland (2007). In terms of drivers' feedback to timer installation, questionnaire surveys were conducted and reported by Wang and Yang (2006) and He et al. (2009), and the results indicated that $87.5 \%$ of surveyed drivers and $93.5 \%$ of pedestrians prefer signal countdown devices to traditional traffic signals. Ma et al. (2010) investigated the impacts of green signal countdown devices and reported an increase in capacity and a reduction in red light violations due to timers in China. Chiou and Chang 
(2010) studied the effect of green signal countdown display (GSCD) and red signal countdown display (RSCD) on driver behavior. Three driver responses to GSCD, including late-stopping ratio, dilemma zone and decision to cross, and three driver responses to RSCD, including early start ratio, start-up delay, and discharge headway are observed and analyzed.

Kidwai et al. (2005) studied the effect of countdown timers on red light running in Malaysia. Three intersections without timers and four intersections with timers were considered and the red light running data were compared. It was observed that the incidences of red light violations were about two times higher in no-timer cases than in cases with timers. Vanajakshi et al. (2010) studied the RLV characteristics under heterogeneous traffic conditions, with and without countdown timers, under Indian traffic conditions. RLV data were collected from two intersections, one with a timer and one without a timer. The results showed a significant difference between the RLV behaviors at the start and end of red without timers. These differences were observed to be insignificant with the presence of a countdown timer. However, the above studies compared RLVs at different locations and hence the effects can be due to other geometric and traffic factors.

Overall, reported studies on headway distribution at signalized intersections and red light violation so far are mainly from homogeneous traffic conditions. However, heterogeneous and less lane disciplined traffic with vehicles occupying the entire width of roadway, may not share the same trends as observed in homogenous cases. Variation in dimensions of different categories of vehicle significantly affects these characteristics with wide-bodied vehicles such as trucks, occupy the full lane, whereas smaller, two- or threewheeled vehicles travel side by side in one lane. During red, these smaller vehicles weave through the bigger vehicles that are in queue and occupy the front of the queue, even beyond the stop line. These vehicles also tend to start moving towards the end of red if the other leg of traffic is not too congested, resulting in red light running. This makes the problem of red light violation and headway distribution under mixed traffic conditions completely different 
from that in the homogeneous traffic conditions. The present study explores this by collecting and analyzing headway and red light violation data under Indian traffic conditions.

Also, there are some studies listed on the effect of timers that compare different intersections with and without timers (Sharma et al. 2009; Ibrahim et al. 2008; Vanajakshi et al. 2010). Studies from other countries in this area report mixed results as detailed in the literature review. Developing standards for such timers will require more studies from different geographical areas. Further, since driver behavior varies widely between countries, there is a need for several separate studies from different geographical locations. The present study concentrates on the effect of these timers on the efficiency and safety of signalized intersections under Indian traffic conditions. A before and after analysis in the presence and absence of countdown timers at the same intersection is carried out in this study in order to exclusively study the effect of the timer, keeping other factors the same.

\section{DATA COLLECTION}

In the present study, a videographic technique was adopted for data collection. Since the signal and timer indication and the corresponding traffic movement are spatially separated, two video cameras were used for the data collection. One camera was used for capturing the signal and timer indication and the other captured the corresponding traffic movement. Since, the data on RLV and headway are in the range of a few seconds, it was important to make sure that these two cameras were synchronized. This was ensured by using special hardware and software which allowed capture of the synchronized feed from the two cameras together. The captured videos were played in the laboratory later to manually extract the required data, which included classified headway and red light violations. Ten days of data were collected from the selected intersection in Chennai, India and are used for the analysis. Data were 
collected from 11AM to 12 PM for 10 days - five with timer and five without timer for the same day of the week.

The selected intersection, as shown in Figure 2, was a four-legged one. The Northbound through movement was selected for the present study. A pre-timed signal control is implemented at the study site with a constant cycle time of 105 seconds. It had 60 seconds red, 39 seconds green and 6 seconds amber during the data collection period. A suitable vantage point was selected, at the intersection from where the signal indication and traffic flow at the stop line could be simultaneously captured. Two cameras were used, one zoomed to record the signal head (and countdown timer, if switched on) and the other recorded the traffic controlled by the above mentioned signal head. Time synchronization was achieved by recording both the video cameras on the same computer. The laptop used screen capture software to time stamp and record the live feed. A sample screen shot is shown in Figure 3.

The data extraction was carried out manually. The classified total number of vehicles moving in each cycle was noted for a total of 170 cycles for each condition. A total of 6,800 two-wheelers, 1,431 auto-rickshaws (motorized 3-wheelers), 192 buses and 4,311 cars were observed without countdown timers. A total of 7,276 two wheelers, 1,438 auto-rickshaws, 174 buses and 4,914 cars were observed with countdown timers. Figure 4 shows the volume distribution per cycle before and after the installation of a countdown timer. It can be seen that the volumes and volume distribution did not change much in the before and after countdown timer cases.

There are multiple factors affecting the queue-discharge characteristics and propensity and intensity of red light running at an intersection. The following parameters were analyzed in this paper: 
○ Time of occurrence: Table 1a lists time of occurrence-related factors that can affect queue discharge characteristics. Due to the presence of start-up lost time, the saturation flow rates are only observed a few seconds after the end of red. Vehicles approaching the intersection at the start or end of red have different attributes that might favor or hinder the propensity of RLV. The factors with positive sign are hypothesized to favor the probability of RLV and the ones with negative sign hinder the probability. As an example, a driver approaching an intersection at the start of red is continuing on the past right of way and will have lower chances of having a conflicting vehicle cross the intersection, whereas a vehicle starting at the end of red will have a higher probability of finding vehicles on the intersection.

○ Phase Information: The presence of information would impact the startup lost times. Table $1 \mathrm{~b}$ lists phase information-related factors that can affect the start up losses and propensity of RLV. When there is no countdown timer, drivers get the warning of onset of red in the form of the amber phase. However, there is no information available regarding when the green is going to start (except for knowing the phase sequence and looking at amber of conflicting phase if possible). In the presence of a phase countdown timer, the drivers have exact knowledge of time remaining for the end of green or end of red. The exact information for end of red may lead to an increase in the propensity of red light runners trying to reduce their delay.

○ Vehicle Characteristics: Generally, two-wheelers have higher maneuverability and acceleration, and therefore have higher saturation flow rates. Table 1c 
lists factors related to vehicle characteristics that can affect the discharge headway and propensity of RLV. Individual vehicle characteristics like acceleration characteristics, maneuverability and size (to reach to the start of queue) and ignition time impact the probability of RLV.

In this paper an empirical study is pursued to determine the properties that have the dominant impact on the queue discharge characteristics and propensity of red light running. It should be noted that the study was carried out using data from one signalized intersection and results and numbers can only indicate the existence of a trend which will have to be corroborated in future by conducting a large scale study with multiple sites.

In the present study, the red light violations were classified based on the following criteria:

1. Timer or no timer

2. Start or end of red

3. Vehicle Type-Cars, Auto Rickshaw, and two-wheelers

The headway was measured by selecting a reference line and noting the time difference between two consecutive vehicles crossing the line. The headways were classified based on the following vehicle. Since many vehicles stop beyond stop line under the Indian traffic conditions, the reference line was selected towards the center of the intersection, instead of the stop line, which is the usual reference point for headway and red light violation studies. The number of red light violations were counted and classified based on i) time of occurrence at start of red or end of red and ii) vehicle type. 


\section{DATA ANALYSIS}

\section{Headway Analysis}

Table 2 lists the distribution of different vehicles in the reduced headway data. The headways, classified based on the following vehicle type, was used in the analysis. Box plots were generated for the observed headway in timer and no-timer conditions and are shown in Figure 5. The groups were based on time elapsed from the start of green time. The text in each box is the median value for that group. The most dramatic effect of the presence of a countdown timer was observed for two-wheelers where the median value of the first group drops from 2.5 seconds to 1.0 second.

The cumulative distribution functions for headways in the first 10 seconds from the start of green (early green) and headway after 10 seconds from the start of green (late green) were compared for timer and no-timer cases for each vehicle type. The hypothesis that the empirical headway distribution for each vehicle types during early/late green is drawn from the same underlying distribution was tested for timer and no-timer cases. Two samples Kolmogrov-Smirnov test (KS-test) was used to test this hypothesis (Eadie et.al. 1971). The KS-test is a non-parametric test and thus makes no assumption about the distribution of the underlying data.

Figure 6 presents the results of the KS-test for all the vehicle types between no-timer and timer cases. The solid line represents empirical distribution function for timer and the dashed line represents the no-timer case. Early green headway distribution, which will influence the startup lost time, is represented by thicker lines. The only null hypothesis to be rejected at $5 \%$ level of significance was for two-wheeler early green. So, the two-wheelers are the only group of vehicles that are statistically significantly affected by the presence of information. It should be noted that late green (surrogate of saturation flow rate) is not significantly affected for any vehicle type. 
The next step of the analysis was to fit the data to a two-regime linear model for all the vehicle types. The first regime would represent the start-up lost time regime and would start with initial high values of headway and gradually settle towards saturation headway, and the second regime would be nearly constant at saturation headway. The change of the first regime to second regime is called the point of inflection. The unknown variables were constant term for first regime, slope of first regime, the point of inflection from first regime to second regime and slope of second regime. Matlab was used to code an exhaustive search on the unknowns to choose the two-regime linear regression model, which can give the lowest mean square error. The result from the search is shown in Figure 7. It can be seen that the two-regime models for all vehicle types are flatter in the presence of a timer because of lower startup losses. As can be observed from queue discharge profile for the study site, there is a need to develop general queue discharge model that can be widely used when the timers are installed. Also, the new queue discharge models will require a change of timing plans for efficient operations at the intersection where timers are installed.

\section{RLV Analysis}

Figure 8 shows a plot of the percentage of cycles seeing red light violations and the number of RLVs averaged over all the cycles having at least one RLV in that category. It can be seen that the volumes and volume distribution did not change much in the before and after countdown timer cases. Since the phase timings, geographic conditions, ambient environment and volume distribution remained the same in the before and after study, any changes in the RLVs can be attributed to the impact of information. The next section presents a detailed analysis on the impact of information on the red light violations. There were very few buses that were observed to violate red light and hence this study does not assess the effect of information on buses. Some of the specific trends that can be noted from Figure 7 are:

1. The number of cycles having red light running at the start of red reduces in the presence of the phase information. While $59 \%$ of cycles had red light violations in 
the absence of phase information display, this drops to $31 \%$ in the presence of phase time information. This implies that most of the drivers use the end of green information to make safe stop decisions. There is a reduction in Mean RLV per RLV cycle, which drops down from 3.32 to 2.30 vehicles.

2. The number of cycles having a red light running at the start of red increases significantly in presence of the phase information. $12 \%$ of cycles had red light violations in the absence of phase information display, which increased to $75 \%$ in the presence of timer. This implies that most of the driver's use the end of red information to reduce their delays in lieu of safety. There is a reduction in Mean RLV per RLV cycle which drops down from 8.52 to 5.60 vehicles. This implies the propensity of RLV increases several fold whereas intensity falls down a notch. The fall in intensity might be due to the huge increase in the observed samples with RLV.

It can also be seen from Figure 7 that the effect of an increase in the number of RLV at the end of red is much more pronounced than the effect on reduction of RLV at the start of red. Thus the presence of information both at the start and end of red leads to an overall increase in the propensity for as well as intensity of RLVs

Analysis of the propensity and intensity of RLVs for individual vehicle types in the presence and absence of phase information was also carried out. For eliminating the bias of the proportional contribution of each vehicle type based on the number of arrivals of each vehicle type, the proportion of the number of red light violations per cycle per unit arrival for that specific vehicle type were used for analysis. This was calculated by dividing the number of red light violations per cycle, for each vehicle type, by the total number of arrivals per cycle of that specific vehicle type. This proportion is termed as "RLV proportion" for the rest of the paper. 
Figure 9 presents the empirical distribution function (CDF) of RLV proportion for with and without countdown timer over all the cycles. The solid line represents the CDF of RLV proportion in the presence of phase information and the dashed line represents the CDF of RLV proportion in the absence of phase information. A two-sample, one-tailed Kolmogorov-Smirnov (K-S) test was conducted to compare the CDFs of RLV proportion with and without phase information.

In case of start of red, the alternate hypothesis tested was that the RLV proportion $\mathrm{CDF}$ for the timer case is larger than in the no-timer case. As an example, for two-wheelers, nearly $50 \%$ of cycles have 0 RLV proportion in absence of phase information at the start of red, and this value jumps to 0.75 in the presence of information. This implies that the red light propensity is reduced for the two wheelers at the start of red due the presence of information. It should also be seen that the CDF curve for no-timer case is shifted to the right once it leaves the zero mark, implying that red light intensity is higher in the cycles for the no-timer case. In the case of end of red, the alternate hypothesis that the RLV proportion CDF for timer cases is smaller than in the no-timer case was tested. The smaller CDF for the timer case implies that a lower number of red light violations occur at lower frequency. Thus the information provided at the end of red would lead to higher red light violations. The results of the K-S test are annotated in each of the CDF plots. The value " $h=1$ " implies that the K-S test rejects the null hypothesis at 5\% significance. The p-value for the test is also provided in each plot.

The main insights that can be drawn from Figure 9 are listed below:

\section{$\underline{\text { Start of Red Analysis }}$}

1. Two-wheelers and cars are the main contributors to red-light violations happening at the start of red. Auto-Rickshaws constitute only a minimal number of RLVs during the start of green. There may be two reasons for this result: Firstly, 
auto-rickshaws do not have high acceleration capabilities and are less prone to accelerating towards the end of green. Secondly, the auto-rickshaws carry passengers for fare and are more cognizant about passenger comfort.

2. There is a statistically significant drop in red light running for both cars and twowheelers at the start of red in the presence of phase information. This can either be because of the fact that both two-wheelers and cars use the presence of phase information to enhance their safety at the start of red or the traffic on other approach start moving and thus reducing the number of red light runner for this approach.

\section{End of Red Analysis}

There is a statistically significant increase in the number of red light violations at the start of green for all three vehicle types. The amount of impact is greater for two-wheelers and autorickshaws as compared to cars. This can be explained by the positioning of these vehicles in the queue. In general, two-wheelers and auto-rickshaws are at the start of queue and have a higher feasibility of violating the red light at the end of red. All the vehicles try to reduce their delay in lieu of safety if the information is provided about the start of green. This observation is in close agreement with the reduction in start-up lost time reported by Sharma et al. (2009) while studying the impact of the timer on queue discharge behavior.

\section{SUMMARY AND CONCLUSIONS}

The results indicate that there is a significant change in the queue discharge models when the phase information is provided. This would require appropriate changes be made to the signal timing plans for optimal operations. The analysis indicates that two-wheelers are significantly affected by the presence of information and there is statistically significant improvement in queue discharge efficiency in the first 10 seconds for two-wheelers. Since the two-wheelers are generally at the start of the queue, this gain in efficiency is translated to the overall queue discharge. 
Red light violations results show that the information provided to the users is used differently during the start or end of red. The information provided at the start of red results in improved safety whereas the information provided at the end of red results in improved efficiency in lieu of safety. In the presence of information, it was found that the propensity of RLV (proportion of cycles having RLV) reduced from $59 \%$ to $31 \%$ at the start of red and at the end of red there was an increase from $12 \%$ to $75 \%$. Also, in the presence of information, the intensity of RLV (Mean RLVs per RLV cycle) for both start of red and end of red reduced from 3.32 to 2.30 vehicles and 8.52 to 5.60 vehicles respectively. The impacts varied based on the vehicle types. These results bring into light the trade-off between safety and efficiency and the choices drivers make in the presence of information. These trade-offs should be carefully considered as the technology advances and drivers are provided more and more information. More studies under varying traffic conditions and geographical conditions will be critical in identifying these trade-offs. With the advent of Intellidrive technology (vehicle to infrastructure communications) the extent of information provided to the drivers should be tailored to achieve system optimality in pre defined objectives. More research is needed with more data under varying traffic conditions to analyze the effect of the time of day, weather conditions and geometric layout on the RLV propensity and intensity in the presence of phase information.

\section{ACKNOWLEDGEMENT}

The second author acknowledges the support through the project CIE/10-11/169/IITM/LELI by Ministry of Urban Development through letter No. N-11025/30/2008-UCD.

\section{REFERENCES}

Association of Selected Intersection Factors with Red-Light-Running Crashes: HSIS Summary Report: FHWA-RD-00-112; http://www.hsisinfo.org/pdf/00-112.pdf

Carstens, R. L. (1971). "Some traffic parameters at signalized intersections.” Journal of Transportation Engineering, ASCE, Vol. 41 -11, , pp. 33-36. 
Chiou, Y. C., Chang, C. H. (2010). “Driver responses to green and red vehicular signal countdown displays: Safety and efficiency aspects." Accident Analysis and Prevention 42. 1057-1065

Craig, N., Mussa, R. N., Sadalla, E. K. , Burns, E. K. and Matthias, J. (1997). "Evaluation of an Alternative Traffic Light Change Anticipation System." Accident Analysis and Prevention (29). No. 2. 201- 209.

Datta, T. K., Schattler, K., and Datta, S. (2000a). "Red Light Violations and Crashes at Urban Intersections.” (CD-ROM). Transportation Research Board of the National Academies, Washington, D.C.

Datta, T. K., Feber, D., Schattler, K., and Datta, S. (2000b). „Low Cost Treatments Result In Effective Safety Improvements.” (CD-ROM). Transportation Research Board of the National Academies, Washington, D.C.

Eadie, W.T., Drijard D., James, F.E., Roos, M., and Sadoulet, B. (1971) Statistical Methods in Experimental Physics. Amsterdam: North-Holland, pp. 269-271.

Federal Highway Administration. Signalized Intersections: Informational Guide, Publication No. FHWA-HRT-04-091.

Greenshields, B. D. (1947). Traffic performance at urban street intersections, Yale University, New Haven, pp. 23 - 27.

Grembek, O., Zhou, K. and Zhang, W. (2009). "Red-Light-Running Collision Avoidance.” California PATH Research Report, UCB-ITS-PRR. 2009-15.

He, Y., Zhang, J., Sun, X., Wei, R. (2009). „Investigating Road Users' Preference on Signal Countdown Devices at Intersections in Beijing.” TRB, Washington.DC.

Highway Capacity Manual. Special report 209 (2000). Transportation Research Board, Washington D. C.,

Horst, V. R. (1988). “Driver Decision Making at Traffic Signals.” Transportation Research Record 1172, TRB, National Research Council, Washington, D.C. 93-97. 
Huey, S. B., and Ragland, D. (2007). "Changes in Driver Behavior Resulting from Pedestrian Countdown Signals.” TRB, Washington, DC.

Ibrahim, M. R. , M. R. Karim and F. A. Kidwai. (2008). "The Effect of Digital CountDown Display on Signalized Junction Performance." American Journal of Applied Sciences 5 (5): 479-482.

Khosla, K., Williams, J.C. (2006). "Saturation Flow at Signalized Intersections During Longer Green Time." Transportation Research Record: Journal of the Transportation Research Board. 1978, Transportation Research Board of the National Academies, Washington, D.C., pp. 61-67.

Kidwai, F. A. , M. R. Ibrahim, and M. R. Karim. (2005). “Traffic Flow Analysis Of Digital Count Down Signalized Urban Intersection." Proceedings of the Eastern Asia Society for Transportation Studies. Vol. 5, pp. 1301 - 1308.

Kunzman, W. (1978). "Another look at signalized intersection capacity." ITE Journal, Vol. 48, pp. 12-15.

Lee, J. and Chen, R.L. (1986). "Entering headway at signalized intersections in a small metropolitan area." In Transportation Research Record: Journal of the Transportation Research Board, No. 1091, Transportation Research Board of the National Academies, Washington, D.C., pp. 117-126.

Limanond, T., Suebpong, C., Roubtonglang, N. (2009). "Effects of countdown timers on queue discharge characteristics of through movement at a signalized intersection." Transportation Research Part C 17. pp.662-671.

Lu, Y. J. (1984). "A study of left-turning maneuver time for signalized intersections." Institute of Transportation Engineers, Vol. 5410, pp. 42-47.

Lum, K. M., and Wong, Y. D. (2002). “A study of stopping propensity at matured red light Camera T-intersections.” Journal of Safety Research, (33), 355-369. 
Lum K. M. and Wong, Y. D. (2003). "Impacts of Red Light Camera on Violation Characteristics.” Journal of Transportation Engineering, (129), No. 6, 648-656.

Lum, K.M. Halim, Harun. (2006). “A before-and-after study on green signal countdown device installation.” Transportation Research Part F. (9), No. 1, 29-41.

Ma, Liu, Yang and Yu. (2010). "Investigating the impacts of green signal countdown devices: an empirical approach and case study in China." 89th TRB Annual Meeting Proceedings (CD-ROM), Washington D.C.,

Mahalel, D., Zaidel, D. (1985a). "A probabilistic approach for determining the change interval." Transportation Research Record. 1069, Transportation Research Board, National Research Council, Washington, D. C., (pp. 39-45).

Mahalel, D., Zaidel, D. M. (1985b). "Safety evaluation of a flashing-green light in a traffic signal." Traffic Engineering \& Control. 26(2), 79-81.

Martinez, K. L., and Porter, B. E. (2006). "Characterizing red light runners following implementation of a photo enforcement program." Accident Analysis and Prevention, (38), No. 5, 862-70.

McGee, H.W. and Eccles, K.A. (2003). "Impact of Red Light Camera Enforcement on Crash Experience," NCHRP Synthesis 310. TRB, Washington, D.C.

Moussavi, M. and Tarawneh, M. (1990). "Variability of departure headways at signalized intersections." Compendium of Technical Papers, Annual Meeting, Institute of Transportation Engineers, pp. 313 - 317.

Nambisan, S. S., and Karkee, G. J. (2010), “Do Pedestrian Countdown Signals Influence Vehicle Speeds?" Transportation Research Record: Journal of the Transportation Research Board. 2149, Transportation Research Board of the National Academies, Washington, D.C., pp. 70-76. 
Newton, C., Mussa, R. N., Sadalla, E. K., Burns, E. K., Matthias, J. (1997). "Evaluation of an alternative traffic light change anticipation system." Accident Analysis and Prevention. 29(2), 201-209.

Parker, M. T. (1996). "The effect of heavy goods vehicles and following behavior on capacity at motorway roadwork sites." Traffic engineering, Vol. 37, pp. 524-531.

Porter, B. E. and England, K. J. (2000). "Predicting Red-Light Running Behavior: A Traffic Safety Study in Three Urban Settings.” Journal of Safety Research, (31), No. $1,1-8$.

Retting, R. A., and Williams, A. F. (1996). "Characteristics of red light runners: results of a field investigation." Journal of Safety Research, (27), 9-15.

Retting, R. A., and Greene, M. A. (1997). "Influence of traffic signal timing on red light running and potential vehicle conflicts at urban intersections." Transportation Research Record 1595, Transportation Research Board, Washington, D. C. 1-7.

Retting, R. A., Williams, A. F. and Greene, M. A. (1998). "Red light running and sensible countermeasures: summary of research findings." Transportation Research Record 1640, Transportation Research Board, Washington, DC., 23-26.

Retting, R. A., Williams, A. F., Farmer, C. M. and Feldman, A. F. (1999). "Evaluation of red light camera enforcement in Oxnard, California." Accident Analysis and Prevention, (31), 169-174.

Retting, R. A., Ferguson, S. A. , Hakkert, A. S. (2003). "Effects of red light cameras on violations and crashes: a review of the international literature." Traffic Injury and Prevention, (4), No. 1, 17-23.

Retting, R. A., Ferguson, S. A. and Farmer, C. M. (2008). "Reducing Red Light Running Through Longer Yellow Signal Timing and Red Light Camera Enforcement: Results of a Field Investigation.” Accident Analysis and Prevention, (40), No. 1. 
Roger, P. R., William, R.M., and Elena S.P. (1998). Traffic Engineering, Prentice Hall, New Jersey.

Sharma, A., Vanajakshi, L. and Rao, N. (2009). "Effect of Phase Countdown timers on queue discharge characteristics under heterogeneous traffic conditions." Transportation Research Record 2130, 93-100.

Thomas, A. A. and Hess, S. (2009). "Red-light cameras for the prevention of road traffic crashes." The Cochrane Library, The Cochrane Collaboration. Published by John Wiley \& Sons, Ltd., Issue 1.

Tong, H.Y., Hung, W.T. (2002). "Neural network modeling of vehicle discharge headway at signalized intersection: model descriptions and results." Transportation Research$A$, Volume 36, Number 1, pp. 17-40.

Vanajakshi, L. D., Sharma, A., Lakshmi, R. (2010). "Red Light Violation Characteristics under Heterogeneous Traffic Conditions: With and Without Countdown Timers." 89th Annual Meeting (CD-ROM), Transportation Research Board, Washington, D.C. Wang, Y., Yang, X., (2006). "Discussion on Setting Traffic Signals with Counting down Display Unit at Intersection Based on Traffic Safety." China Safety Science Journal. $16(3), 54-60$. 


\section{LIST OF FIGURES}

Figure 1. Variation in headway at start of green

Figure 2. Test site

Figure 3. Screen shot of the data collected using synchronized video setting

Figure 4. Volume distribution per cycle before and after the installation of countdown timer

Figure 5. Headway distribution with Timer and No-Timer

Figure 6. Empirical headway distribution for No-Timer and Timer

Figure 7. Queue discharge models for No-Timer and Timer

Figure 8. Cumulative percentage of cycles seeing red-light violations and mean RLV per cycle

Figure 9. Cumulative distribution function for RLV proportion categorized by vehicle types at the start and end of red 


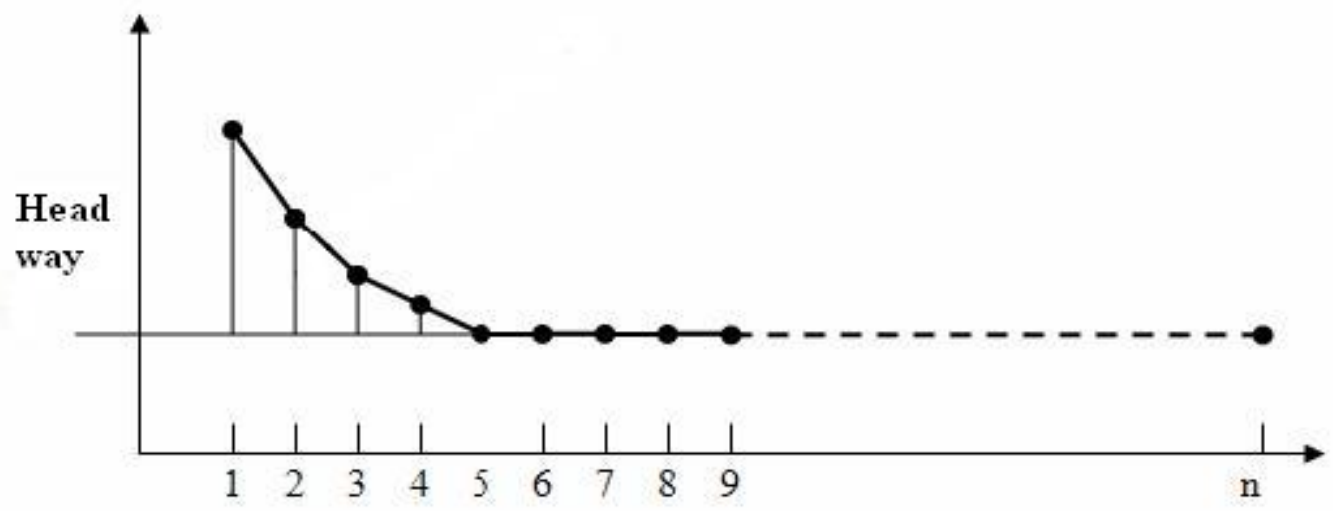

Queue position

Figure 1. Variation in headway at start of green

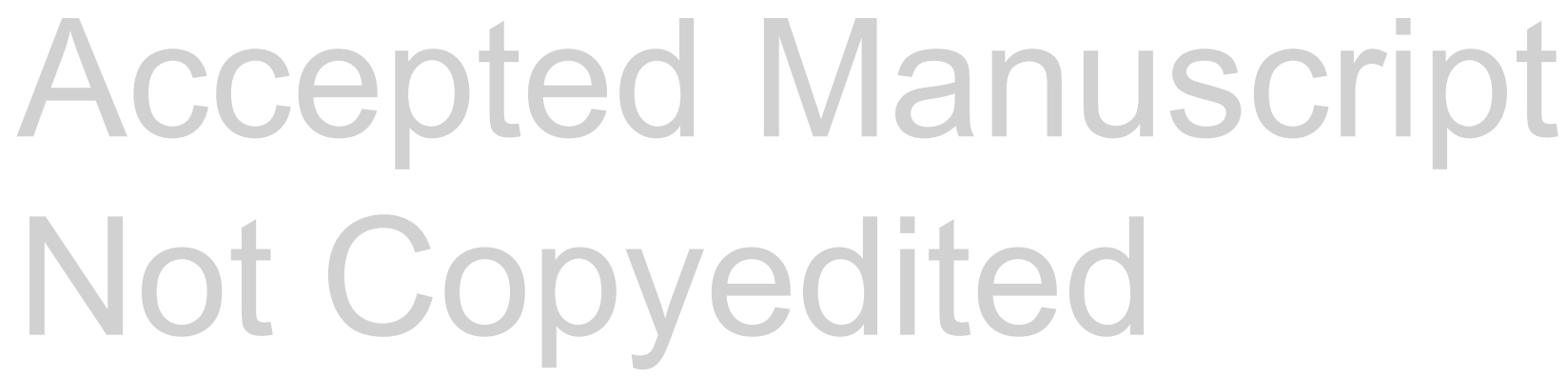




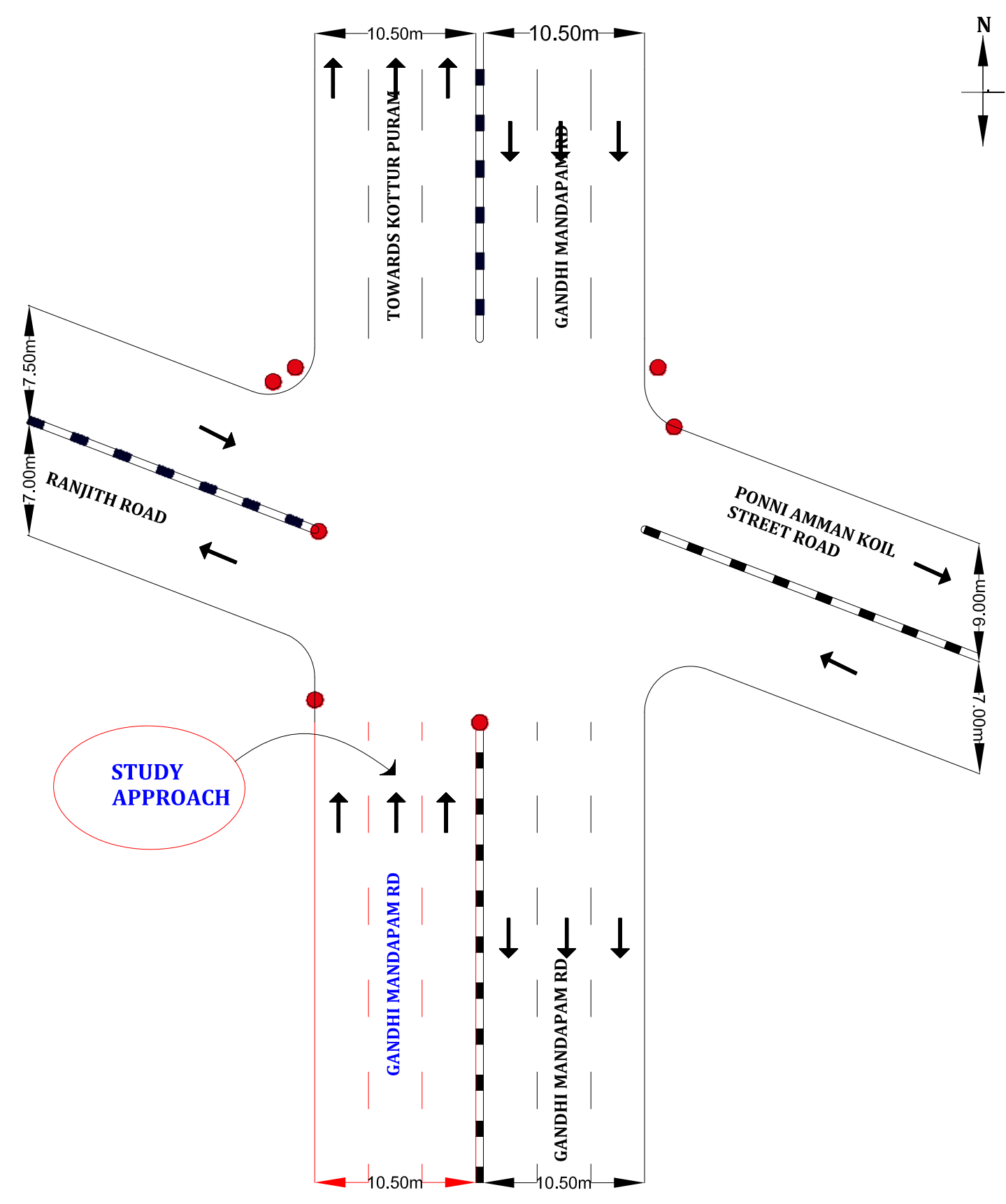

Figure 2. TEST SITE

TRAFFIC SIGNAL POINTS

SCALE 1:200

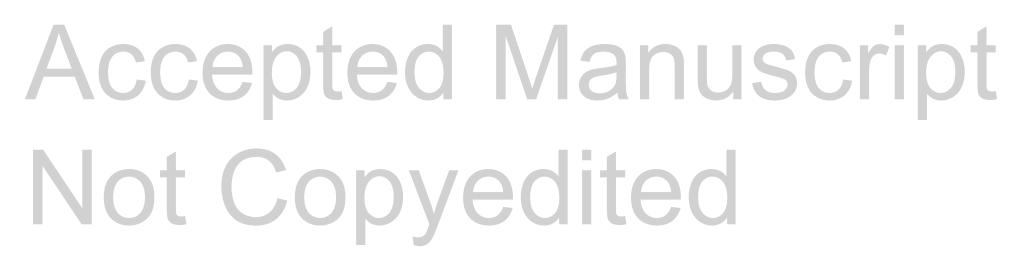

Copyright 2011 by the American Society of Civil Engineers 

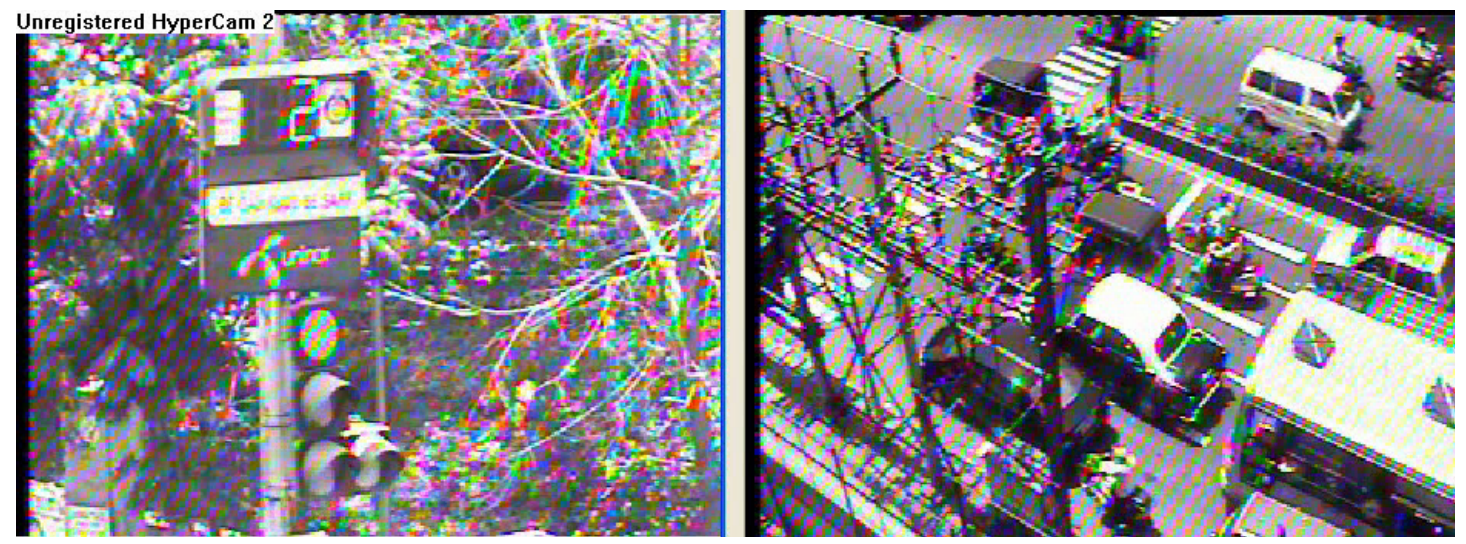

Figure 3. Screen shot of the data collected using synchronized video setting

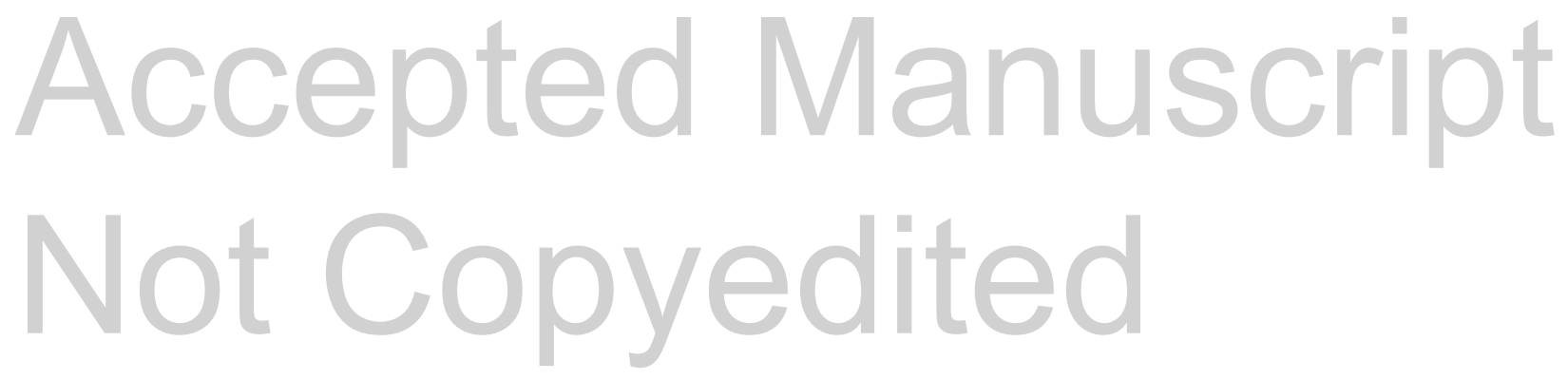




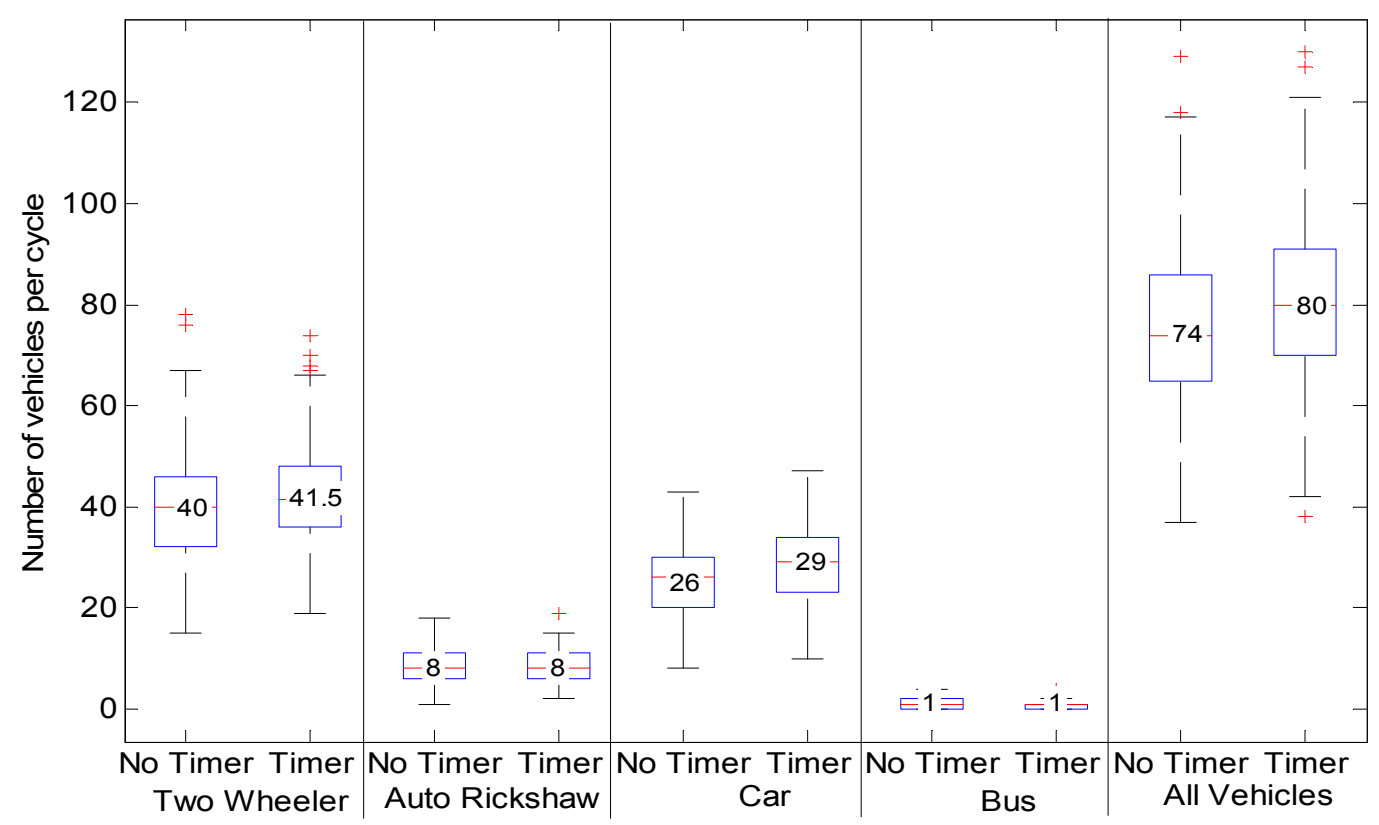

Figure 4. Volume distribution per cycle before and after the installation of countdown timer

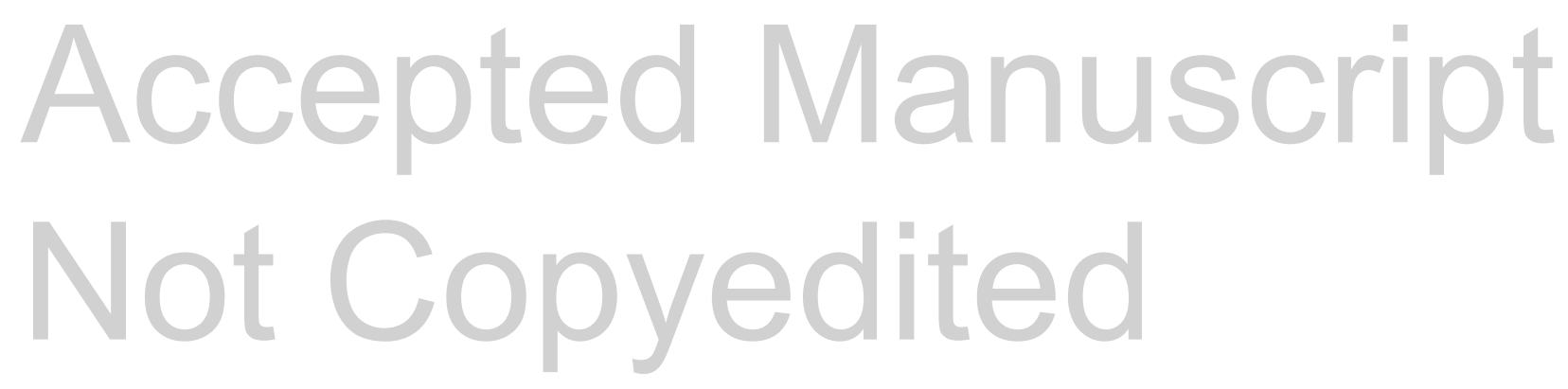


No Timer
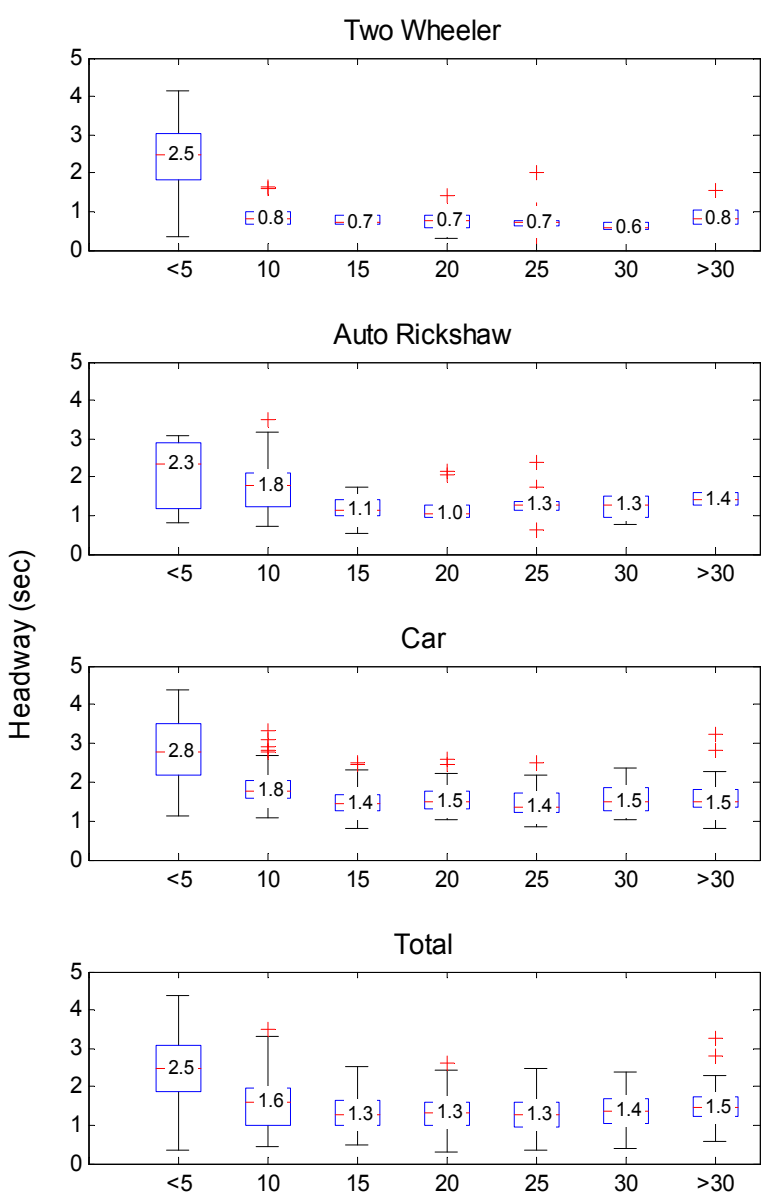

Timer
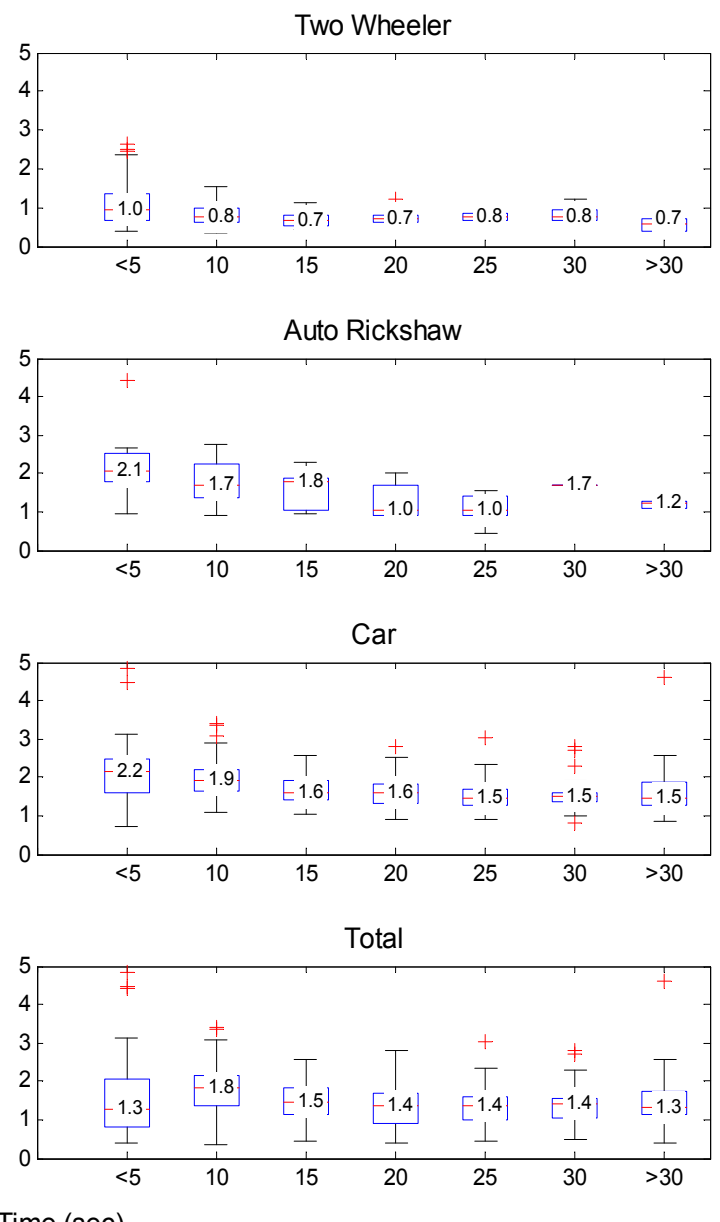

Figure 5. Headway distribution with Timer and No-Timer

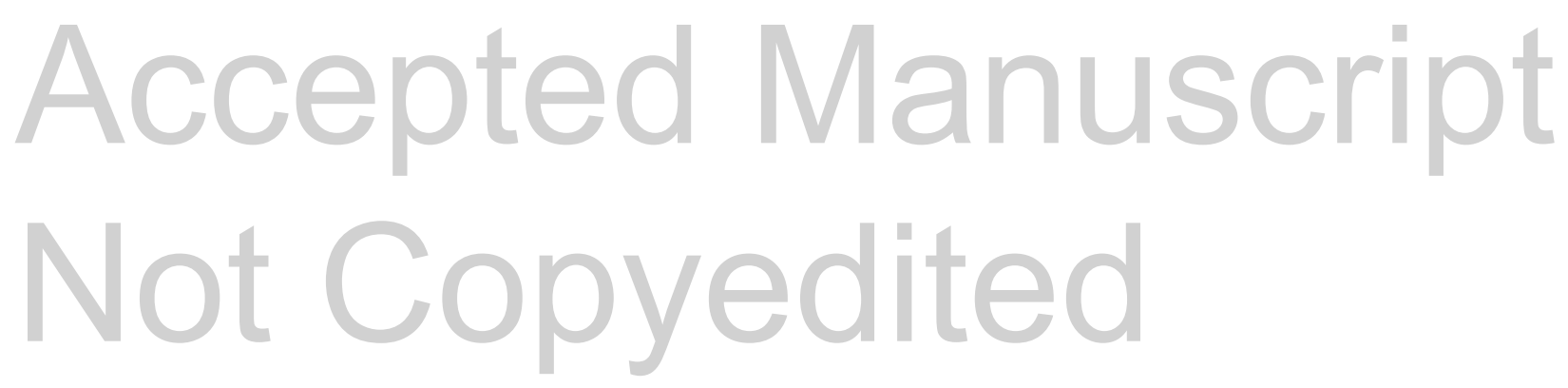




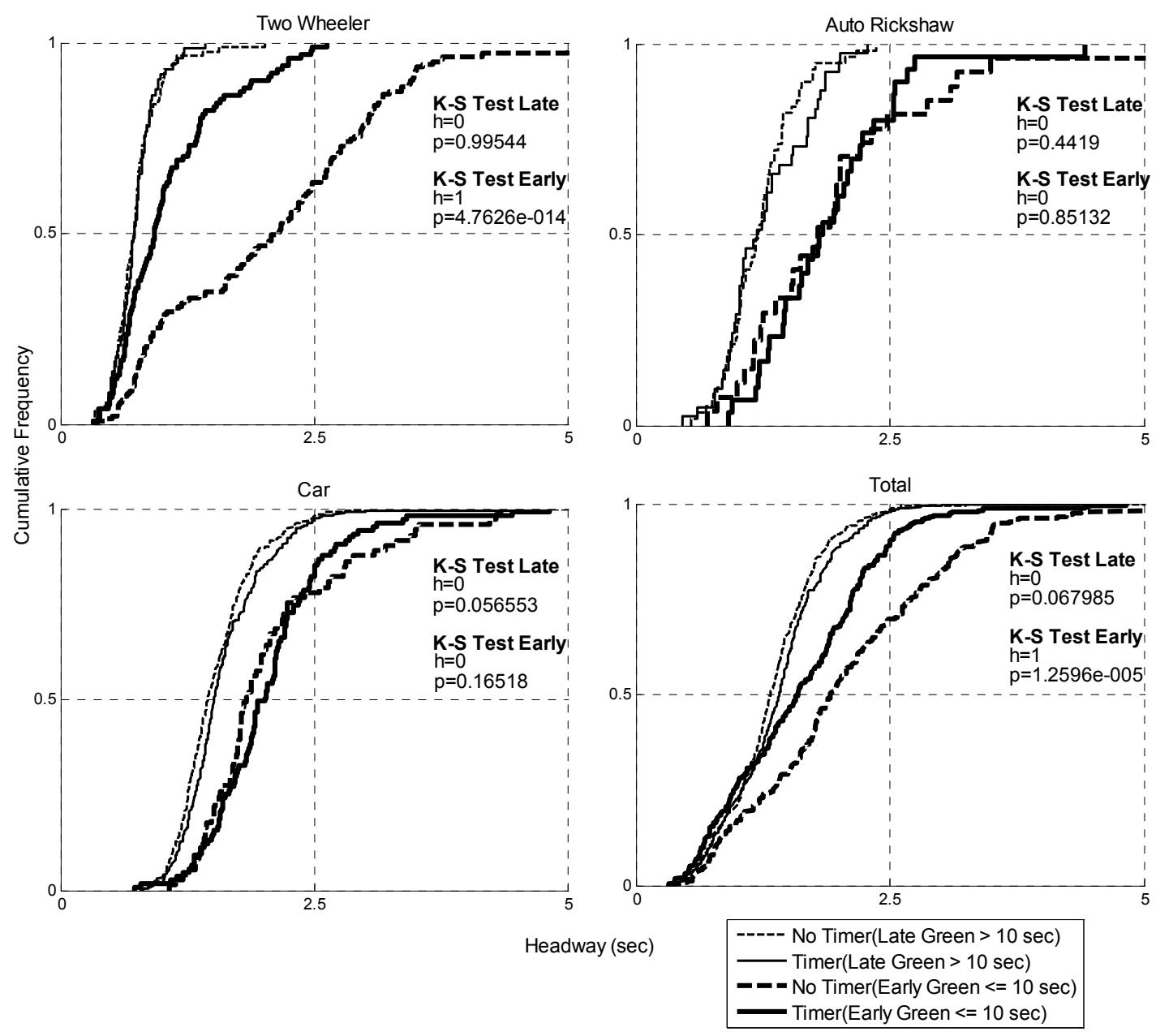

Figure 6. Empirical headway distribution for No-Timer and Timer

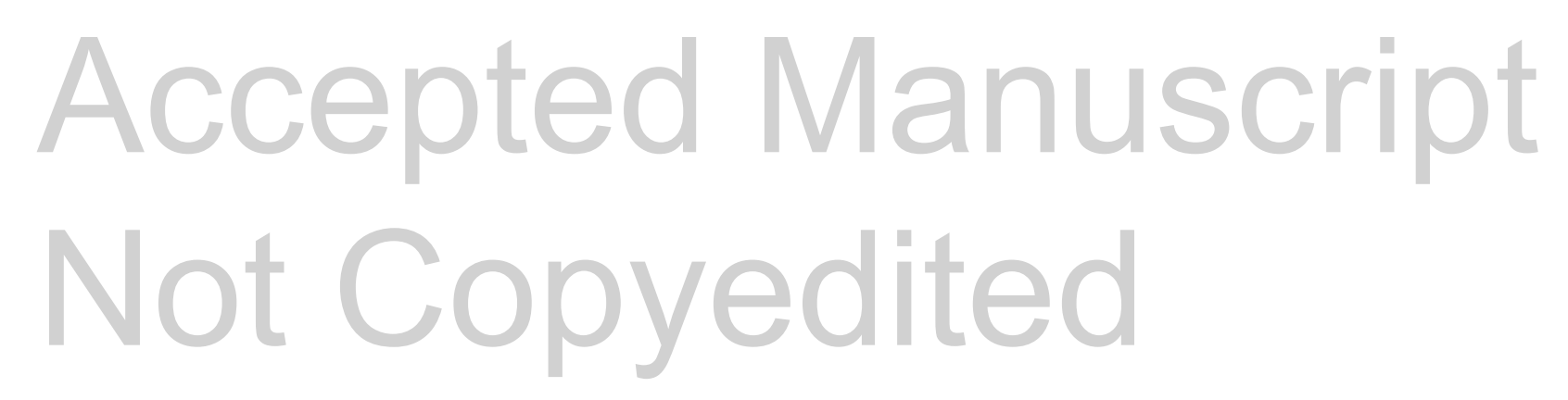


No Timer

Two Wheeler

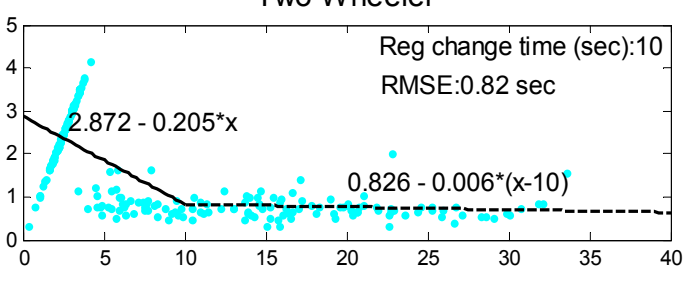

Auto Rickshaw
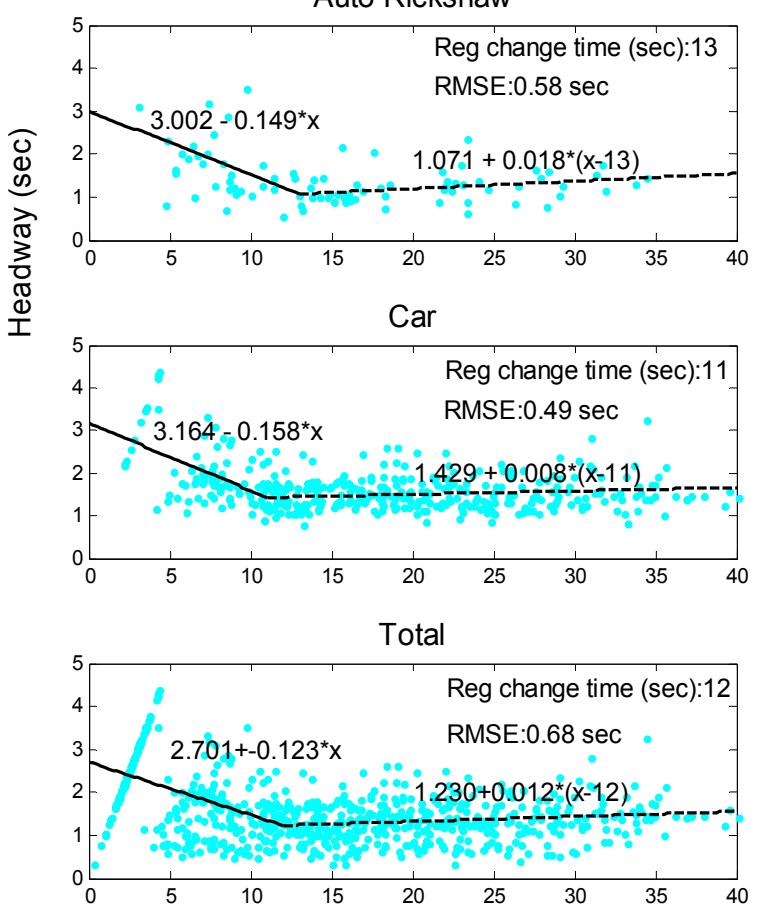

Timer

Two Wheeler

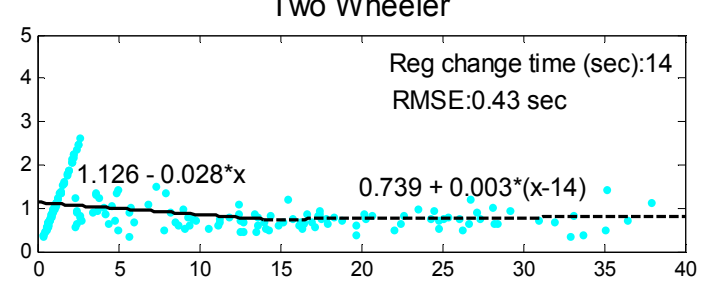

Auto Rickshaw

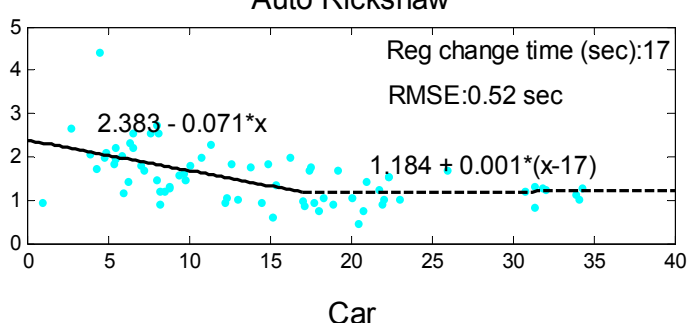

Car

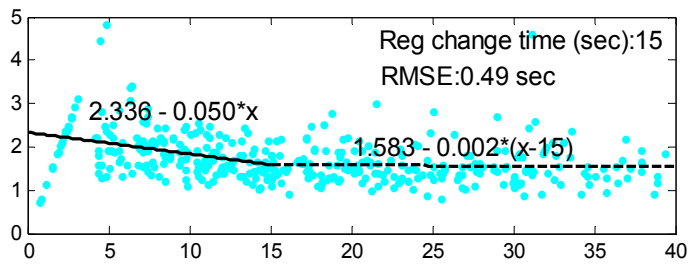

Total

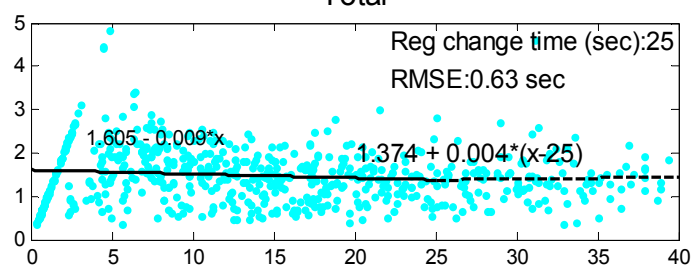

Green Time (sec)

Figure 7. Queue discharge models for No-Timer and Timer

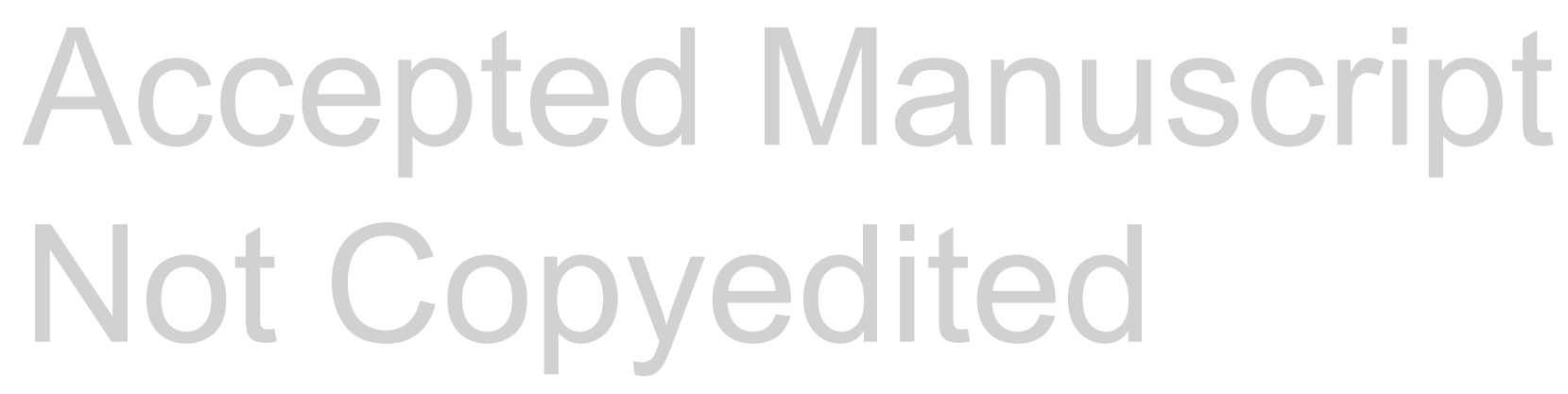




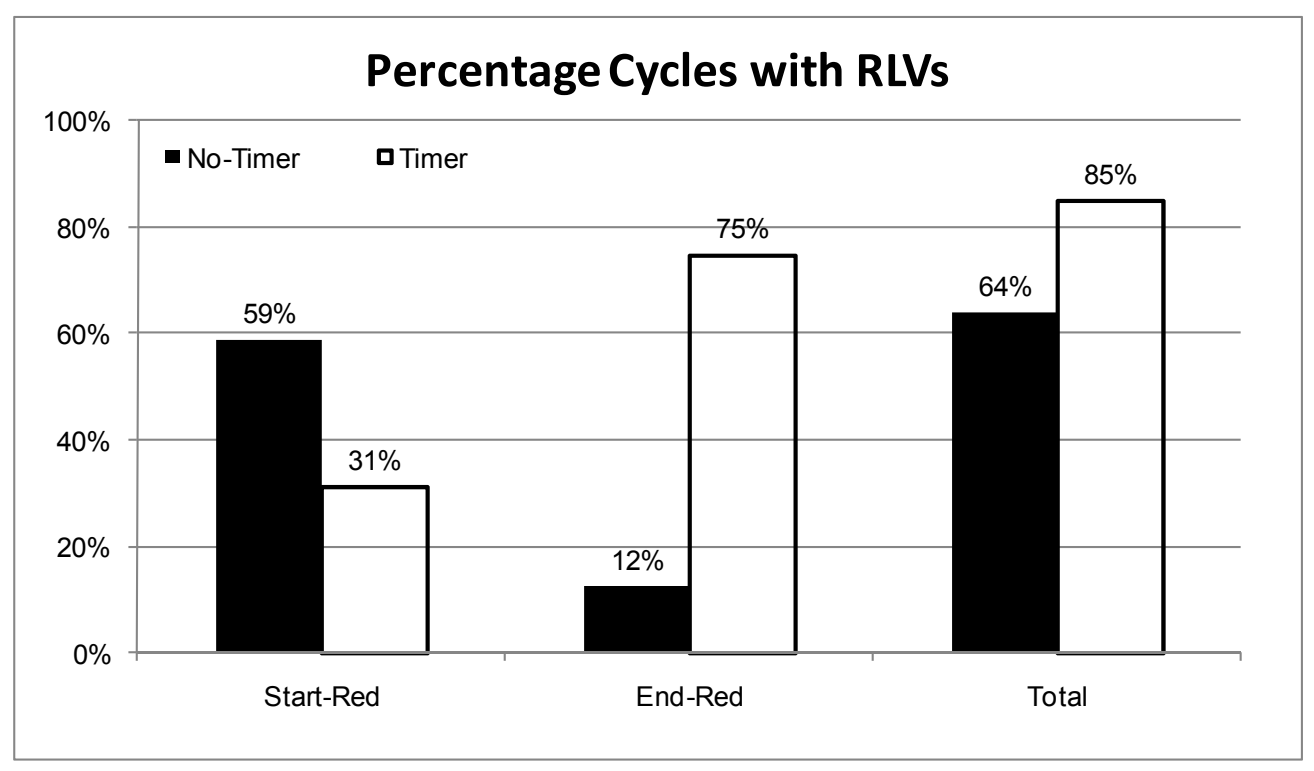

a) Percentage of cycles with RLV

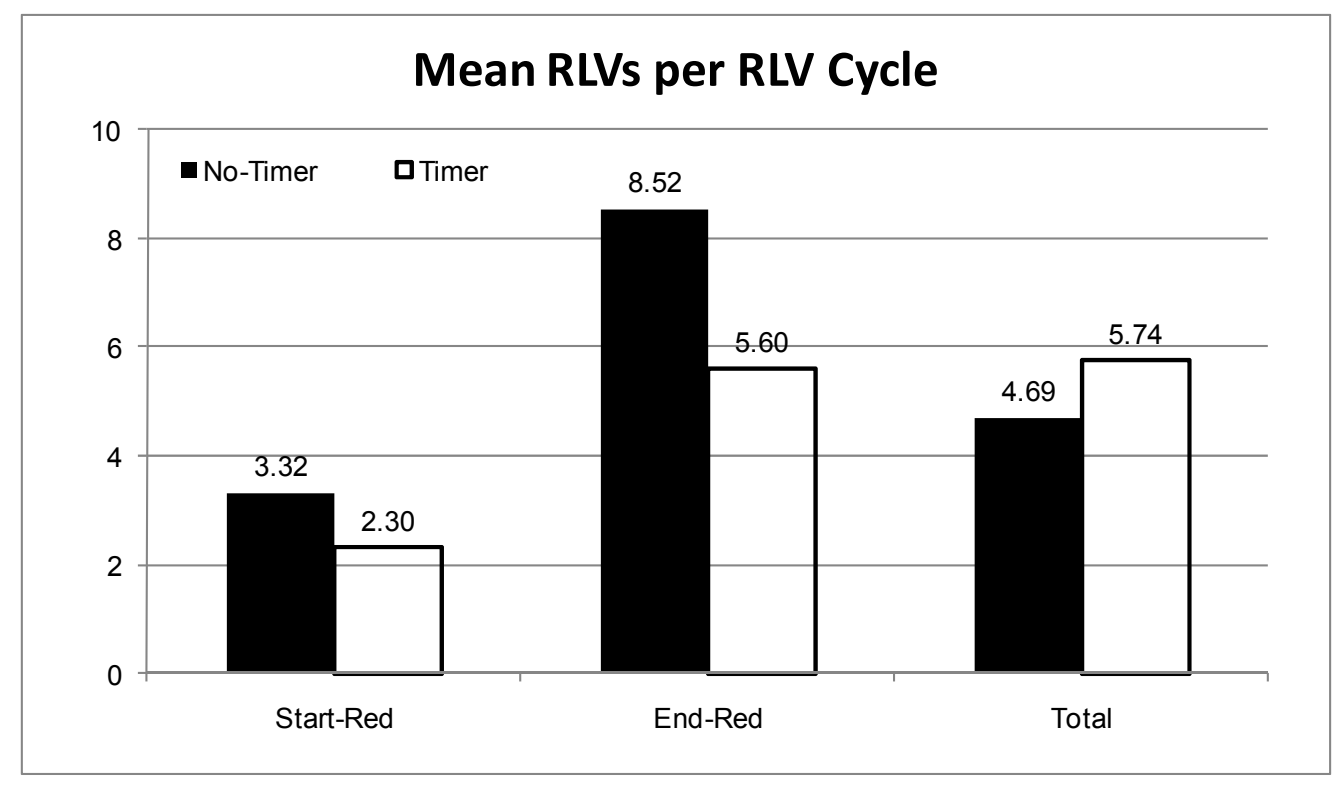

\section{b) Mean RLVs per RLV Cycle}

Figure 8.Cumulative percentage of cycles seeing red-light violations and mean RLV per cycle 

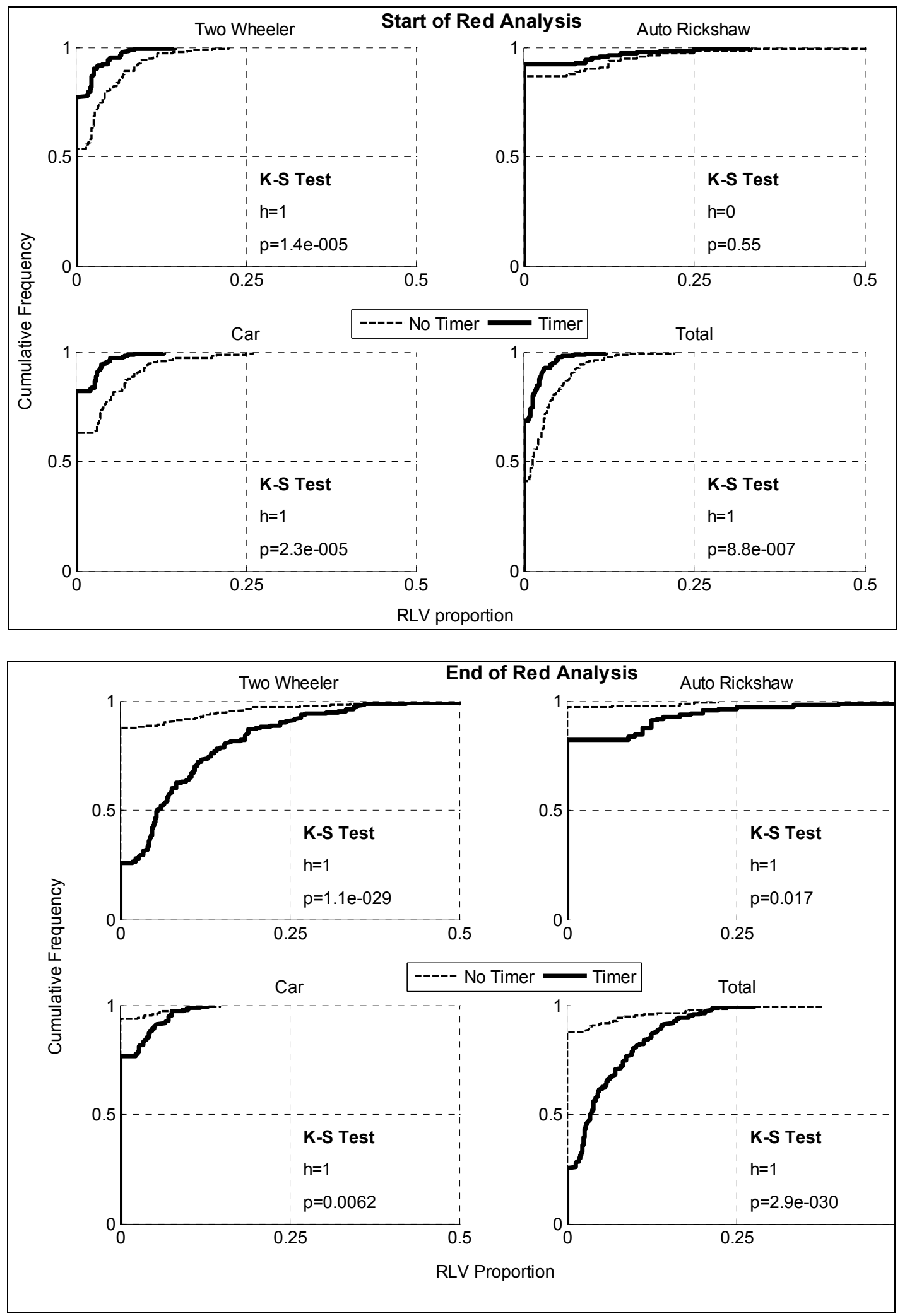

Figure 9. Cumulative distribution function for RLV proportion categorized by vehicle types at the start and end of red 
Table 1. Properties affecting the propensity of RLV at an intersection

\section{a) Time of occurrence}

\begin{tabular}{|l|l|}
\hline Start Red & End Red \\
\hline+ High initial speed & - Starting from stop \\
+ Continue on the past right of way & - Infringe on the post right of way \\
- High acceleration not possible & + High acceleration not possible \\
\hline
\end{tabular}

\section{b) Phase information available to the driver}

\begin{tabular}{|l|l|}
\hline No-timer & Timer \\
\hline - Warning on onset of red by yellow & - Exact information on end of green but \\
phase & the same information at yellow \\
- No information on end of red & +Exact information for end of red \\
\hline
\end{tabular}

c) Vehicle characteristics

\begin{tabular}{|l|l|l|l|}
\hline Cars & Auto Rickshaw & Two wheelers & Bus \\
\hline + High & - lower & + Highest & - lowest \\
possible & acceleration power & acceleration & acceleration power \\
-Generally & - occupying & possible & - generally \\
occupying last & red & +generally & occupying last row \\
positions during & - slowest ignition & positions during & - slower ignition \\
red & time & red & time \\
+ Fast ignition time & & + fast ignition time & \\
\hline
\end{tabular}


Table 2: Distribution of vehicle headway in the reduced data

\section{a. No Timer}

\begin{tabular}{|c|c|c|c|c|c|}
\hline & Car & TW & Auto & Total & Percent \\
\hline$<5 s e c$ & 15 & 101 & 3 & 119 & $15 \%$ \\
\hline $5-10$ & 58 & 38 & 24 & 120 & $15 \%$ \\
\hline $10-15$ & 85 & 25 & 18 & 128 & $16 \%$ \\
\hline $15-20$ & 77 & 25 & 16 & 118 & $15 \%$ \\
\hline $20-25$ & 62 & 20 & 14 & 96 & $12 \%$ \\
\hline $25-30$ & 49 & 11 & 8 & 68 & $9 \%$ \\
\hline$>30$ & 44 & 5 & 5 & 54 & $7 \%$ \\
\hline Total & 390 & 225 & 88 & 703 & \\
\hline Percent & $50 \%$ & $29 \%$ & $11 \%$ & & \\
\hline
\end{tabular}

\section{b. Timer}

\begin{tabular}{|c|c|c|c|c|c|}
\hline & Car & TW & Auto & Total & Percent \\
\hline$<5$ sec & 36 & 84 & 7 & 127 & $16 \%$ \\
\hline $5-10$ & 71 & 17 & 23 & 111 & $14 \%$ \\
\hline $10-15$ & 73 & 20 & 10 & 103 & $13 \%$ \\
\hline $15-20$ & 58 & 21 & 12 & 91 & $12 \%$ \\
\hline $20-25$ & 49 & 11 & 10 & 70 & $9 \%$ \\
\hline $25-30$ & 39 & 12 & 1 & 52 & $7 \%$ \\
\hline$>30$ & 35 & 6 & 8 & 49 & $6 \%$ \\
\hline Total & 361 & 171 & 71 & 603 & \\
\hline Percent & $56 \%$ & $26 \%$ & $11 \%$ & & \\
\hline
\end{tabular}

